\title{
Estimation of Spinal Loading during Palletizing under Restricted Height and Poor Lighting
}

\author{
Abdulrahman $\mathrm{A}^{1}$, Davis $\mathrm{KG}^{1 *}$, Kotowski $\mathrm{SE}^{2}$ and Marras $\mathrm{WS}^{3}$ \\ ${ }^{1}$ Low Back Biomechanics and Workplace Stress Laboratory, University of Cincinnati, USA \\ ${ }^{2}$ College of Allied Health Sciences, University of Cincinnati, USA \\ ${ }^{3}$ The Spine Institute, The Ohio State University, USA
}

*Corresponding author: Kermit G Davis, Low Back Biomechanics and Workplace Stress Laboratory, University of Cincinnati, Environmental Health, 423 Kettering Lab, 160 Panzeca Way, Cincinnati, OH 45267-0056, USA, Email: Kermit.davis@uc.edu

Way, Cincinnati, 0H 45267-0056, USA, Email: Kermit.davis@uc.edu

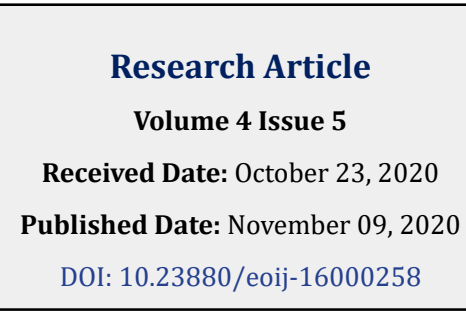

\section{Abstract}

Many industries have areas with restricted spaces where manual material handling occurs which is oftentimes further complicated by poor lighting. The study objective was to evaluate the spine loading when lifting boxes within restricted height space with different light levels. Ten participants lifted boxes with independent variables: restricted height, light levels, pallet layer, and pallet position. The dependent variables included three-dimension spine loads and rating of perceived exertion. The results indicate that importance of location of the box as well as the restricted height of the space where the box is being lifted (increase of about $1200 \mathrm{~N}$ in compression and $160 \mathrm{~N}$ in A-P shear). Under general lifting conditions, light level had minimal impact (under $100 \mathrm{~N}$ ). Gender was also found to have a significant impact for lateral shear and A-P shear forces (males > females for lateral shear but < for A-P shear). Overall, restricted height and location of on the pallet had the greatest impact on the spine loads.

Keywords: Low Back Disorders; Spinal Loading; Manual Material Handling

\section{Introduction}

Low back disorders (LBDs) are considered to be one of the most prevalent health problems in many physically demanding industries such as manufacturing, warehousing, and health care. The 2010 Global Burden of Disease Study placed LBDs as \#1 with the highest number of years lived with disability and \#6 in account to the disability-adjusted life years $[1,2]$.

Manual Material Handling (MMH), which involves moving or handling objects by lifting, pushing, pulling, lowering and holding, has been linked to increased risk of low back injuries [3-5]. It was found that MMH workers' compensation claims represent a large source of the general claim and costs [6]. Workplace factors define the work conditions that a worker has to encounter when lifting. Factors such as location of the box (e.g. height, distance, and asymmetry) at the origin and destination define the lifting demands works demands during typical depalletizing tasks [7-11]. Origin height was one of the dominant factors in the development of spine loads and corresponding LBD risk $[9,10]$. Those studies were conducted under normal work place conditions where there were no height limits (e.g. restricted or confined space) and the work area was well lit.

In many industries, there are countless items that are lifted and handled from areas considered to be restricted height spaces (e.g. low ceiling heights where workers cannot stand upright) under poor lighting conditions such as warehousing, mining, retail stores, and oil and gas companies. Lifting within restricted height potentially requires accuracy to maneuver around boxes or under a low ceiling, which translating into awkward postures [12,13]. Another study 
by Gallagher, et al. [14] reported lumbar spine experienced a linear increase in the peak loading as the vertical distance of the ceiling was reduced. Lifting under low restricted heights can be further complicated by poor light [15]. To date, no studies have investigated how lighting levels influence how someone lifts and the corresponding biomechanical responses within the spine. Thus, the objective of this study was to investigate the impact of light level and restricted height on the spine loads when lifting boxes from a pallet to a cart.

\section{Methods and Materials}

\section{Study Overview}

This ergonomic laboratory simulation study is designed to evaluate the spinal loading and rating of perceived exertion. The independent variables consisted of position on a pallet, layer on pallet, light level, and restricted height. Each subject completed the lifting tasks for the restricted height space, layer, and lighting conditions in a blocked manner, which was counterbalanced among the subjects. For each lift conditions, participants lifted from a set 5 positions on the pallet to 5 positions on the cart (order same every time).

\section{Participants}

Ten healthy participants (5 males and 5 females) completed the study. Age of the subjects ranged between 18 to 40 years and subjects reported no history of back disorders in the past six (6) months (summary of anthropometry in Table 1). The participants were recruited from the students and individuals around the University of Cincinnati using a flyer. All participants completed a consent process that was approved by the Institutional Review Board prior to the start of the study. Participants were compensated for their time and effort.

\begin{tabular}{|c|c|c|}
\hline Gender & Male (5) & Female (5) \\
\hline Age (years) & $30.2(7.8)$ & $28.8(6.4)$ \\
\hline Standing Height (cm) & $171.9(3.8)$ & $167.4(7.7)$ \\
\hline Weight $(\mathrm{kg})$ & $85.2(8.0)$ & $60.6(5.9)$ \\
\hline Shoulder height (cm) & $141.1(2.0)$ & $138.5(6.5)$ \\
\hline Elbow Height (cm) & $105.2(3.3)$ & $103.5(5.3)$ \\
\hline Hip Height (cm) & $95.4(6.3)$ & $98.7(8.2)$ \\
\hline Knee Height (cm) & $52.9(2.6)$ & $50.9(3.8)$ \\
\hline Trunk Breadth (cm) & $33.0(5.0)$ & $31.4(4.7)$ \\
\hline Trunk Depth (cm) & $25.5(6.7)$ & $1.8(3.7)$ \\
\hline
\end{tabular}

Table 1: Anthropometry measurements for the participants in the study.

\section{Study Design}

Independent Variables: There are four independent variables in this study: 1) light level, 2) restricted height space, 3) layer on pallet, and 4) position on pallet. The light level conditions had three levels of luminance: poor-1 foot candle (fc), fair-5 fc, and good-10 fc. Restricted height space had two levels with ceiling height at 1) $122 \mathrm{~cm}$ (lower) and 2) $150 \mathrm{~cm}$ (high) (Figure 1). Layer of the pallet had two levels: top (at $56.5 \mathrm{~cm}$ to center of box) and 2) bottom (at $26 \mathrm{~cm}$ to center of box). There were 5 positions on the pallet which consisted of: 1) front-right, 2) front-left, 3) middle, 4) backright, and 5) back-left.

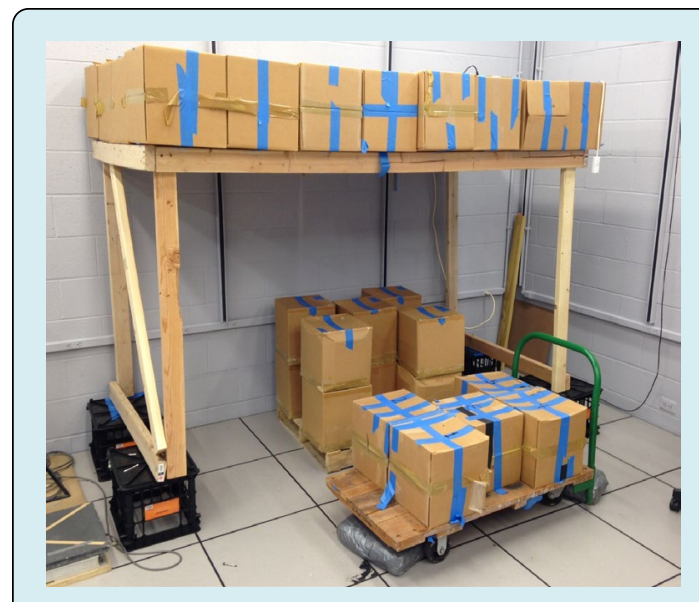

(A)High restricted height space

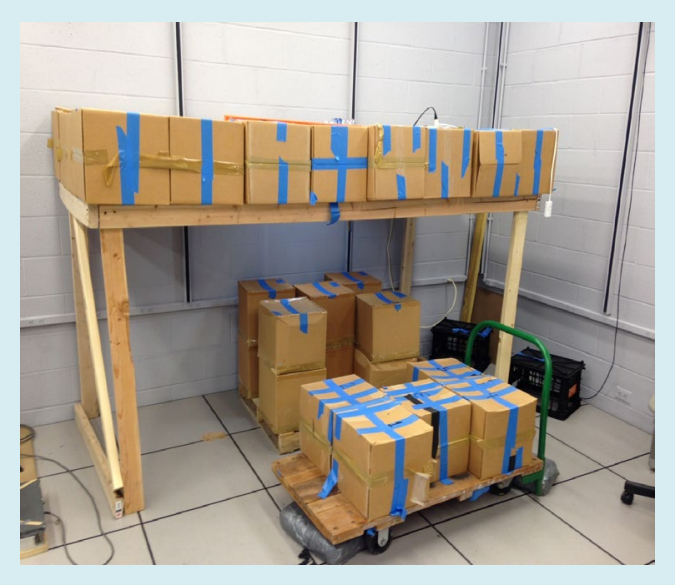

b) Low restricted height space

Figure 1: Two Restricted Heights: a) High and b) Low.

Dependent Variables: There were two primary dependent variables measurements were collected: 1) peak three- dimensional spine loading including compression, lateral shear and anterior-posterior shear forces as predicted by 
an EMG-assisted spinal loading model $[9,10,16-20]$ and 2) Borg Rating of Perceived Exertion (RPE) [21]. Spine loading was estimated through the well validated EMG-assisted biomechanical model developed by the Ohio State University $[7,9,10,16-20]$. The biomechanical spine model uses the muscle activity for the ten major trunk muscles (left and right pairs of the latissimus dorsi, erector spinae, rectus abdominis, external obliques, and internal obliques) and three-dimensional trunk kinematics (as quantified by the lumbar motion monitor) [22,23] to predict the spine load. In order to assess the relative risk of the spine loads, spine strength tolerances were used as benchmarks $(3400 \mathrm{~N}$ in compression [24] and $750 \mathrm{~N}$ in shear [25]). This model has been carefully validated in different conditions of manual material handling $[7,26,27]$.

The rating of perceived exertion was rated through the Borg scale. The ratings were collected immediately after completing each set of 5 lifts under a given set of conditions (e.g. restricted height, pallet layer, and light level). The exertion rating scale from 6 to 20 was shown to the subjects as visual aid and their verbal ratings were recorded by lab staff using a data collection sheet. This rating scale has been broadly used by ergonomists to study exertion perception in different work sittings such as clinical, laboratory, and occupational [21,28-31].

\section{Experimental Set-Up}

A restricted height space was created with structure was made out of wood and a ceiling made from cardboard boxes as marked by tape on the floor (Figure 1). A standard wood pallet was positioned at the center of the restricted height space area. Boxes were positioned on the pallet in predetermined positions based on whether the conditions were the bottom or top layers. In order to set the two heights of the restricted height spaces, crates were used to lift up the wooden structure for the high height with no crate under the structure for the low height. A light was placed in the ceiling of the structure that allowed the illuminance level to be adjusted through a dimmer switch to the specific lighting levels ( $1 \mathrm{fc}, 5 \mathrm{fc}$, and $10 \mathrm{fc}$ ) at the center of the pallet. A fourwheel flatbed cart was placed adjacent and parallel to the pallet, which served as the destination for all conditions (Figure 1). The location of the cart was fixed as marked by tape with wheels locked.

The boxes that were lifted weighed $9.1 \mathrm{~kg}$ and were standard cardboard $(30.5 \mathrm{~cm}$ by $30.5 \mathrm{~cm}$ by $30.5 \mathrm{~cm})$ with no handles. The boxes were filled with sand to the specific weight. In addition, the bottom of the boxes were wrapped with duct tape to reinforcement them. Finally, the top was marked with a number that corresponded to the positions on pallet and cart to ensure participants lift in correct pattern for all conditions.

\section{Experimental Procedures}

After consent process was completed, participants were introduced to the lab staff, given thorough instructions about the lifting tasks they would be asked to perform, and provided limited information about the data collection procedures. EMG electrodes were placed on subjects' skin following standardized procedures [20]. A series of static maximum exertions were completed in order to normalize the muscle activity data (including trunk flexion, trunk extension, lateral bend right, lateral bend left, twist right, twist left, latissimus dorsi pull-down right, and latissimus dorsi pull-down left). Participants were verbally encouraged by the investigator to perform as close to a real maximum exertion as possible [20]. These signals were processed, rectified, and filtered with a high pass filter at $30 \mathrm{~Hz}$ and al low pass filter at $1000 \mathrm{~Hz}$, and integrated using a 40 millisecond rolling smoothing filter. After completing the MVC conditions, the participants were fitted with a LMM and then positioned on the calibration lift system for calibration lifts to determine muscle gain for the model [32]. These calibration lifts permitted the model to accurately predict estimates without relying on having feet stationary on the force plate $[7,11,19,33,34]$.

Before starting the lifting conditions, the lab lights were turned off and subjects were asked to wait for their eyes to adjust to the lighting condition of the trial (Approximately 5 minutes). Subjects were provided with the following instructions: start lifting when verbally signaled to start (e.g. "Go ahead and lift"), lift at a comfortable pace, do not throw or toss boxes (e.g. maintain control), lift one box at a time, and lift from the designated layer. Lifting technique was not controlled and was left to each participant (e.g. selfselected). A set of lifts were completed for each condition, which consisted of a restricted height space, light condition, and layer on the pallet. The lifting conditions were counterbalanced on restricted height space so the structure did not have to be adjusted for every condition with the light level and layer being randomized. Perceived exertion ratings were collected directly after de-palletizing of a layer of boxes for the given condition. Between each study condition, subjects were given at least five minutes rest before proceeding with the next condition. During this rest period, lab staff set up the next condition by returning the boxes back to the pallet and adjusting luminance level.

\section{Statistical Analysis}

Descriptive statistical analyses such as mean, standard deviation and maximum values were calculated to evaluate outliers and general trends. Repeated measures analysis of variance (ANOVA) was used to analyze the data, and identify 
whether there are significant changes in the dependent variables as function of independent variables. In order to account for inherent individual differences variation, subjects was utilized as random blocking factor. Post hoc analysis in the form of studentized Tukey tests were performed to identify the sources of significant effects. All statistical analyses were completed using SAS statistical software (SAS, Inc., Carey NC).

\section{Results}

The results for the analysis of variance (ANOVA) indicated several significant main and interaction effects for spine loading and Rating of Perceived Exertion (RPE). For spine loads (Table 2), layer on pallet significantly impacted all three spine loads while restricted height significantly impacted compression and anterior-posterior (A-P) shear forces. Light level only had a significant impact on lateral shear. Gender was found to influence shear loads (lateral and A-P). As seen in the table, a few two-factor interactions were found to be significant for spine loads. The statistical results for rating of perceived exertion (RPE) had only two main effects-restricted heights $(\mathrm{p}<0.0001)$ and gender $(\mathrm{p}=0.01)$ and one interaction effect-restricted height by gender $(p=0.05)$.

\begin{tabular}{|c|c|c|c|}
\hline Independent Variables & Compression & Lateral Shear & Anterior-Posterior Shear \\
\hline Light Level & 0.16 & $\mathbf{0 . 0 2}$ & 0.11 \\
\hline Restricted Height & $<\mathbf{0 . 0 0 0 1}$ & 0.58 & 0.0009 \\
\hline Position on Pallet (Position) & 0.17 & 0.52 & $\mathbf{0 . 0 0 9}$ \\
\hline Layer on Pallet (Layer) & $\mathbf{0 . 0 2}$ & $\mathbf{0 . 0 4}$ & $\mathbf{0 . 0 0 0 1}$ \\
\hline Gender & 0.46 & $<\mathbf{0 . 0 0 0 1}$ & 0.98 \\
\hline Light Level* Restricted Height & 0.17 & 0.30 & 0.79 \\
\hline Position*Light Level & 0.85 & 0.93 & 0.94 \\
\hline Layer*Light Level & 0.63 & 0.88 & 0.92 \\
\hline Gender*Light Level & 0.66 & 0.99 & 0.73 \\
\hline Gender*Layer & 0.52 & 0.23 & $\mathbf{0 . 0 1}$ \\
\hline Restricted Height*Position & 0.89 & 0.05 & 0.91 \\
\hline Restricted Height*Layer & 0.13 & 0.58 & 0.47 \\
\hline Gender*Restricted Height & $\mathbf{0 . 0 2}$ & $\mathbf{0 . 0 1}$ \\
\hline Position*Layer & 0.69 & 0.22 & \\
\hline Gender*Position & 11 & \\
\hline
\end{tabular}

Table 2: Summary of the statistical analyses for the Three Dimensional Spine Loads (shaded and bold values indicate significant effect at $\mathrm{p}<0.05)$.

\section{Spine Loads}

Peak compression force was found to be lower for the high restricted height conditions (about $5900 \mathrm{~N}$ ) as compared to the low restricted height condition (about 7100 N) (Figure 2). A similar trend was seen for A-P shear force with high at about $800 \mathrm{~N}$ and low at $960 \mathrm{~N}$ (Figure 2). While gender had no main effect on peak compression, there was a small interaction effect with restricted height where females had slightly higher compression values (360 N) for the high restricted height while the males had higher values $(700 \mathrm{~N})$ for low restricted height.

As expected, peak compression, A-P shear and lateral shear were greatest in the bottom layer of the pallet with a difference of $580 \mathrm{~N}, 100 \mathrm{~N}$, and $125 \mathrm{~N}$, respectively. There was an interactive effect for restricted height and layer of pallet for lateral and A-P shear forces where the only differences between restricted heights were for the top layer of the pallet (130 N for Lateral shear and $275 \mathrm{~N}$ for A-P shear) (Figure 3).

Level of light had a minimal impact with only a small impact on the lateral shear force with an increasing loads with increasing light level (about $80 \mathrm{~N}$ per $5 \mathrm{fc}$ ) with higher light-low at $620 \mathrm{~N}$, medium at $720 \mathrm{~N}$, and high at $800 \mathrm{~N}$. A complex result for light value and restricted height was found for A-P shear where low and medium light level had more impact in the low restricted height (about 230 and $340 \mathrm{~N}$, respectively) and no significant difference for high light level.

Gender was also found to have a significant impact for lateral shear and A-P shear forces (males > females for lateral shear 
but $<$ for A-P shear). Males were found to have about $880 \mathrm{~N}$ and $600 \mathrm{~N}$ in lateral shear and A-P shear, respectively while females had $500 \mathrm{~N}$ and $1200 \mathrm{~N}$, respectively. While there was not an overall difference between genders for peak compression, males had larger forces in the left front and back positions by about $800 \mathrm{~N}$ (first two boxes lifted for a layer) while females had larger loads in the middle and right front and back by about $300 \mathrm{~N}$ (last three boxes lifted for a layer).

\section{Rating of Perceived Effort}

The perceptions of the lifting exertion were found to be impacted by restricted heght (low-11.1 vs high-9.0), gender (male-10.5 vs female-9.6) and the interaction between restricted height and gender (Figure 4). The difference between the genders was generally in the low restricted height (1.3 points). Males also had a larger diference between the low and high restricted conditions ( 2.6 vs 1.7 difference).

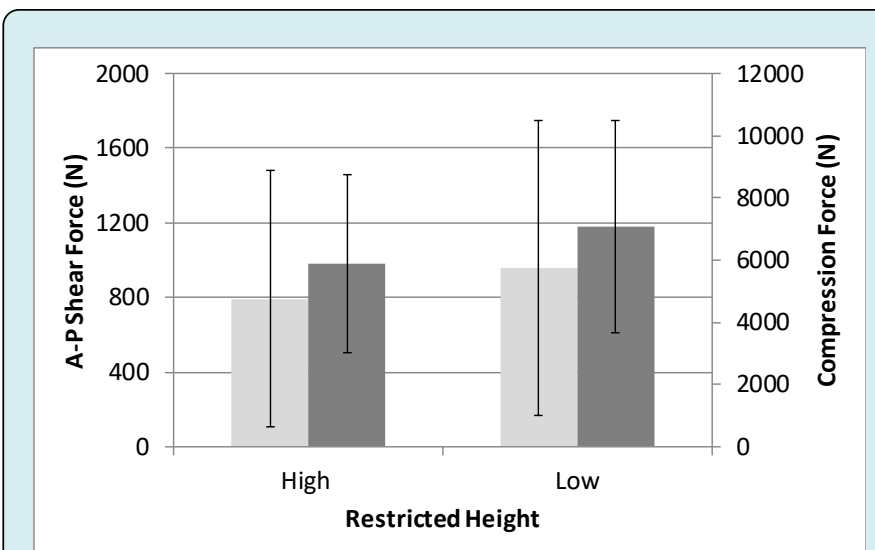

Figure 2: Peak Compression and Anterior-Posterior Shear Force as a Function of Restricted Height.

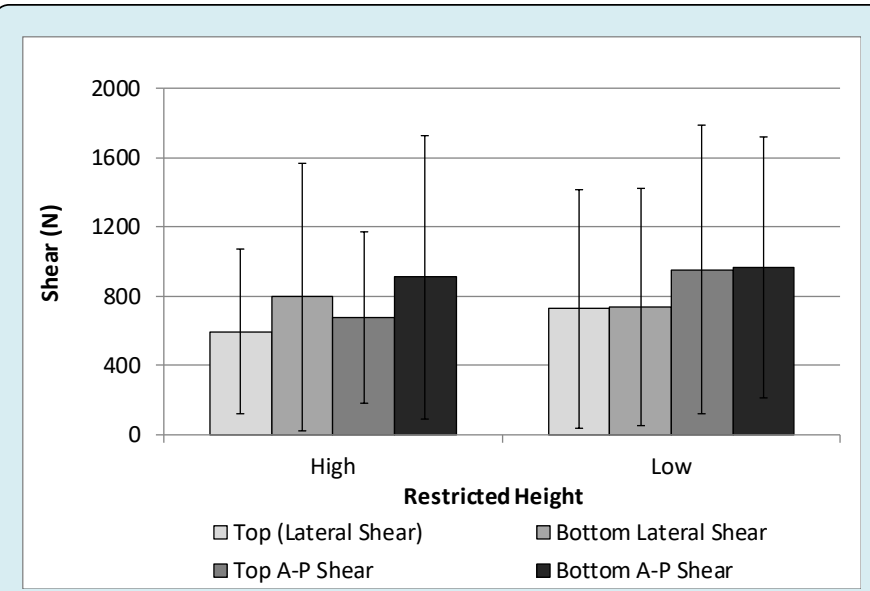

Figure 3: Mean Peak Lateral and Anterior-Posterior Shear Force as a Function of Restricted Height and Layer of Pallet.

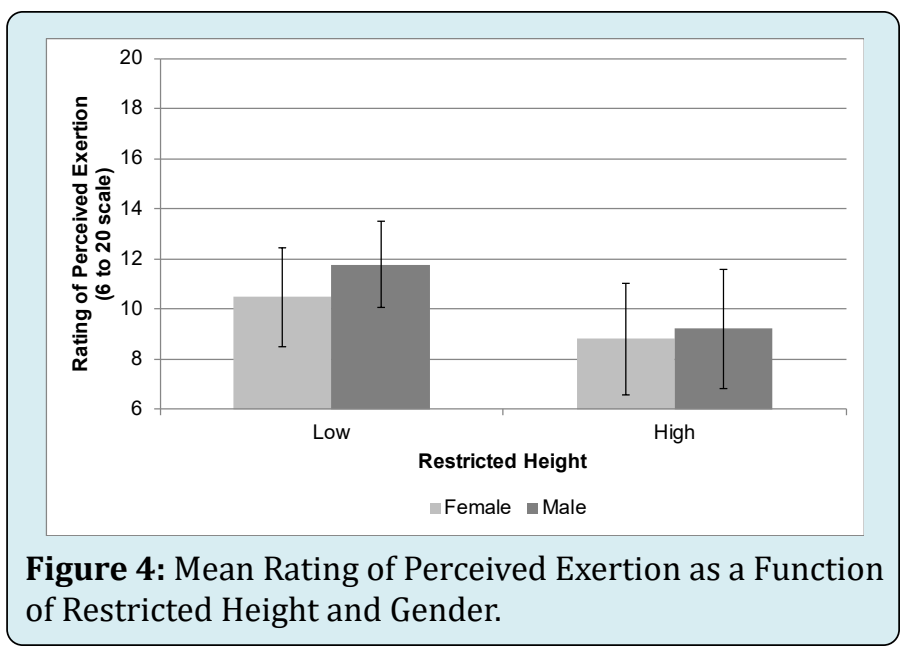

\section{Discussion}

Several important results were found in the current study. First, light level had limited impact on the spine loads, only minimally influencing the lateral shear loads (about $80 \mathrm{~N}$ to $100 \mathrm{~N}$ ). To date, there has been no study to investigate the impact of light on how a person lifts and the corresponding spine loads. Many of the trunk muscles produced greater activity with more lighting but the impact was most likely was offset by small changes in the trunk motions. Overall, these muscle activity differences had minimum impact on the spine with respect to the impact of lift level. The bottom line is that better lighting in confined areas may reduce some of the complex loads being placed on the spine.

Second, restricted height had a large impact on the spine loads with a $1200 \mathrm{~N}$ increase in compression and a $160 \mathrm{~N}$ increase for A-P shear force when lifting under the low restricted height as compared to the high restricted height. The low restricted height also had loads that approached the spine tolerance limits for compression and shear [24,25]. Other researchers have found low ceiling height (as in mining environments) increased the loads on the spine [14]. As with previous studies [14], low restricted height caused the person to lift in more sagittally flexed postures (about $4^{\circ}$ ) but they reduced the twisting (about $3^{\circ}$ ) and how fast they moved their trunk (e.g. slower sagittal and twisting velocity (about $8^{\circ} / \mathrm{s}$ and $5^{\circ} / \mathrm{s}$, respectively) for low restricted height). An increase in muscle coactivity ( $4 \%$ to $5 \% \mathrm{MVC}$ ) was found for the low restricted height, both antagonistic and agonistic muscles. The combination of increased muscle coactivity and sagittal flexion for low restricted height likely lead to the high spine loads.

Third, as expected, where the box was lifted from on the pallet had a significant impact on the three-dimensional spine loads. The largest impact was for the layer of the pallet where the bottom layer had the highest loads: more 
than $580 \mathrm{~N}$ in compression, $100 \mathrm{~N}$ in lateral shear, and 125 $\mathrm{N}$ in A-P shear. The bottom layer produced spine loads that approached tolerance levels, especially when combined with the low restricted height. Marras, et al. [9] found very similar spinal loads for the lower layers of the pallet (the two lowest layers in their study had similar compression and shear loads as the two layers in current study). There was no impact of position on the pallet on the spine loads which was somewhat surprising based on previous research [10]. The lack of influence for the position on the pallet may be attributed to the lifting task and ability to walk around the pallet. While some of the trunk kinematics did show small differences between pallet positions, the biomechanical relevance of these differences were likely minimal.

Fourth, gender had significant impact on the spine loads but it was completely inconsistent in that lateral shear forces were greater for males but A-P shear was lower as compared to females. Males also had greater compression for the low restricted height but no difference was found for the high restricted height. Studies by Marras, et al. [35,36] also found higher compression and shear forces for males during symmetric and asymmetric lifting. The current study certainly provides further evidence that females are not "scaled down" males as the genders lift boxes differently $[35,36]$. Females lifted with significantly more sagittal flexion and more sagittal motion, especially when lifting under the high restricted height.

Finally, the subjective perceptions provided further evidence that the restricted height had the largest impact on the individuals with the low restricted height having the highest RPEs. One of the more interesting results was that males had higher RPEs than females as it would be expected that the demands would be greater for the females. The difference between males and females was greatest when lifting in the low restricted height conditions where it may be more demanding for males due to the feeling of being scrunched between the low ceiling and the boxes. The bottom line is that lifting in the more restricted height resulted in higher perceptions of exertion, mainly for the males.

In order to understand and interpret the results, a few considerations need to be discussed. First, the sample number of subjects is relatively small $(n=10)$.The small number is typical of most biomechanical laboratory studies and given the within subjects repeated measures design, the statistical power should be sufficient enough to identify biologically meaningful differences between the different effect levels. The small numbers did limit the variability in the anthropometry which could have influenced the results such as taller people being more impacted by restricted height.
Second, there were only two levels of restricted height and layer on the pallet. A lower restricted height or reduced distance between the top of the boxes and the bottom of the ceiling may further influence the way the worker would lift the boxes and potentially produced greater spine loads due to more awkward postures and muscle coactivation.

Third, the assessment focused on spine loading and did not consider loading on other joints such as upper extremity and shoulder. The biomechanical loading of these joints could be impacted significantly, resulting in more adverse conditions for those joints. Trade-offs were likely and need to be investigated to truly understand impact of lighting and restricted height on workers.

Fourth, the participants were given a short time to adjust to the given light levels, which was concentrated on the pallet. This time ensured that the conditions were consistent for all conditions but may have had some carry over effects from one light condition to the next. This may be one reason why there was a limited effect of light level on spine loads. However, the randomization of the conditions would minimize this effect. Overall, these potential limitations would likely have had limited impact on the current results but do lead to the need to expand the investigation of restricted height, position on the pallet, and light level.

\section{Conclusion}

The results of the study provided strong evidence that low restricted height spaces adversely impacted the threedimensional loads on the spine. The low restricted height increased the compression by $1200 \mathrm{~N}$ and A-P shear force by $160 \mathrm{~N}$ compared to the high restricted height. Light level had minimal impact on the spine loads. Similar to previous research, the low layer increased the three-dimensional spine loads, most likely due to increased sagittal flexion and muscle coactivation. Out of the factors investigated during the current study, restricted height and layer of the pallet had the greatest impact on the spine loads.

\section{References}

1. Hoy D, March L, Brooks P, Blyth F, Woolf A, et al. (2014) The global burden of low back pain: estimates from the Global Burden of Disease 2010 study. Annals of the Rheumatic Diseases 73(6): 968-974.

2. Murray CJL, Vos T, Lozano R, Naghavi M, Flaxman AD, et al. (2012) Disability-adjusted life years (DALYs) for 291 diseases and injuries in 21 regions, 1990-2010: A systematic analysis for the Global Burden of Disease Study 2010. The Lancet 380(9859): 2198-227. 
3. Bigos SJ, Spengler DM, Martin NA, Zeh J, Fisher L, et al. (1986) Back injuries in industry: A retrospective study. II. Injury factors. Spine 11(3): 246-251.

4. Lavender SA, Marras WS, Ferguson SA, Splittstoesser RE, Yang G (2012) Developing Physical Exposure-Based Back Injury Risk Models Applicable to Manual Handling Jobs in Distribution Centers. Journal of Occupational and Environmental Hygiene 9(7): 450-459.

5. Spengler DM, Bigos SJ, Martin NA, Zeh J, Fisher L, et al. (1986) Back injuries in industry: A retrospective study. I. Overview and cost analysis. Spine 11(3): 241-245.

6. Dempsey PG, Hashemi L (2004) Analysis of workers' compensation claims associated with manual material handling. Ergonomics 42(1): 138-195.

7. Davis KG, Marras WS, Waters TR (1998) Reduction of Spinal Loading Through the Use of Handles. Ergonomics 41(8): 1155-1168.

8. Davis KG, Marras WS, Waters TR (1998) Evaluation of the Spinal Loading during Lowering and Lifting. Clinical Biomechanics 13(3): 141-152.

9. Marras WS, Granata KP (1997) Spine loading during trunk lateral bending motion. Journal of Biomechanics 30(7): 697-703.

10. Marras WS, Granata KP, Davis KG, Allread WG, Jorgensen MJ (1997) Spine Loading and Probability of Low Back Disorder Risk as a Function of Box Location on a Pallet. Human Factors in Manufacturing 7(4): 323-336.

11. Marras WS, Granata KP, Davis KG, Allread WG, Jorgensen MJ (1999) Effects of Box Features on Spinal Loading during Order Selecting. Ergonomics 42(7): 980-996.

12. Gallagher S (2005) Physical limitations and musculoskeletal complaints associated with work in unusual or restricted postures: a literature review. Journal of Safety Research 36(1): 51-61.

13. Gallagher S, Hamrick CA (1992) Acceptable workloads for three common mining materials. Ergonomics 35(9): 1013-1103.

14. Gallagher S, Hamrick CA, Cornelius KM, Redfern MS (2001) The effects of restricted workspace on lumbar spine loading. Occupational Ergonomics 2(4): 201-213.

15. van Bommel IW, van den Beld IG, van Ooyen IM (2002) Industrial lighting and productivity. Philips Lighting, The Netherlands.

16. Granata KP, Marras WS (1993) An EMG-assisted model of loads on the lumbar spine during asymmetric trunk extensions. Journal of Biomechanics 26(12): 1429-1438.

17. Granata KP, Marras WS (1995) An EMG-assisted model of trunk loading during free-dynamic lifting. Journal of Biomechanics 28(11): 309-317.

18. Marras WS, Granata KP (1995) A biomechanical assessment and model of axial twisting in the thoracolumbar spine. Spine 20(13): 1440-1451.

19. Marras WS, Davis KG, Jorgensen M (2002) Spine loading as a function of gender. Spine 27(22): 2514-2520.

20. Mirka GA, Marras WS (1993) A stochastic model of trunk muscle coactivation during trunk bending. Spine 18(11): 1396-1409.

21. Borg GA (1982) Psychophysical bases of perceived exertion. Medicine and Science in Sports and Exercise 14(5): 377-381.

22. Marras WS, Fathallah FA, Miller RJ, Davis SW, Mirka GA (1992) Accuracy of a three dimensional lumbar motion monitor for recording dynamic trunk motion characteristics. International Journal of Industrial Ergonomics 9(1): 75-87.

23. Marras WS, Lavender S, Leurgans S, Rajulu S, Allread WG, et al. (1993) The role of dynamic three-dimensional trunk motion in occupationally related low back disorders: the effects of workplace factors, trunk position, and trunk motion characteristics on risk of injury. Spine 18(5): 617-628.

24. Waters TR, Putz Anderson V, Garg A, Fine LJ (1993) Revised NIOSH equation for the design and evaluation of manual lifting tasks. Ergonomics 36(7): 749-776.

25. Gallagher S, Marras WS (2012) Tolerance of the lumbar spine to shear: a review and recommended exposure limits. Clinical Biomechanics 27(10): 973-978.

26. Davis KG, Marras WS (2005) Load spatial pathway and spine loading: how does lift origin and destination influence low back response?. Ergonomics 48(8): 10311046.

27. Ferguson SA, Gaudes-MacLaren LL, Marras WS, Waters TR, Davis KG (2002) Spinal loading when lifting from industrial storage bins. Ergonomics 45(6): 399-414.

28. Borg GA (1970) Perceived exertion as an indicator of somatic stress. Scandinavian Journal of Rehabilitation Medicine 2(2): 92-98.

29. Borg GA (1973) Perceived Exertion: A note on "history" 
an methods. Medicine and Science in Sports 5(2): 90-93.

30. Borg GA (1990) Psychophysical scaling with applications in physical work and the perception of exertion. Scandinavian Journal of Work, Environment, and Health 16(S1): 55-58.

31. Borg G, Hassmen P, Lagerstrom M (1987) Perceived exertion related to heart rate and blood lactate during arm and leg exercise. European Journal of Applied Physiology 56(6): 679-685.

32. Fathallah FA, Marras WS, Parnianpour M (1998) An assessment of complex spinal loads during dynamic lifting tasks. Spine 23(6): 706-716.

33. Davis KG, Jorgensen MJ, Marras WS (2000) An Investigation of Perceived Exertion via Whole Body Exertion and Direct Muscle Force Indicators During the
Determination of the Maximum Acceptable Weight of Lift. Ergonomics 43(2): 143-159.

34. Jorgensen MJ, Davis KG, Kirking BC, Lewis KEK, Marras WS (1999) The Significance of Biomechanical and Physiological Variables During the Determination of the Maximum Acceptable Weight of Lift. Ergonomics, 42(9): 1216-1232.

35. Marras WS, Jorgensen MJ, Davis KG, (2000) Effect Foot Movement and an Elastic Lumbar Support on Spinal Loading during Free-Dynamic Symmetric and Asymmetric Lifting Exertions. Ergonomics 43(5): 653668.

36. Marras WS, Davis KG, Jorgensen MJ (2003) Gender Influences on Spine Loads during Complex Lifting. The Spine Journal 3(2): 93-99. 